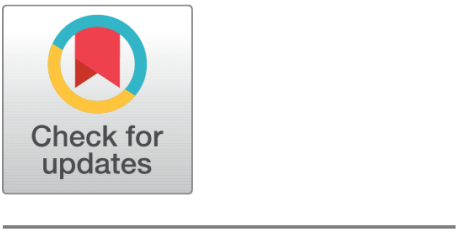

OPEN ACCESS

Received: 16.09 .2020

Accepted: 05.10.2020

Published: 03.11 .2020

Editor: Dr. Natarajan Gajendran

Citation: Markad NT, Mahadik S (2020) Broadband circular polarized patch antenna with harmonic suppression. Indian Journal of Science and Technology 13(38): 4073-4083. https://doi.org/ 10.17485/IJST/v13i38.1682

* Corresponding author.

Tel: +91-8668385685

swapnali.mahadik2722@gmail.com

Funding: None

Competing Interests: None

Copyright: (c) 2020 Markad \& Mahadik. This is an open access article distributed under the terms of the Creative Commons Attribution License, which permits unrestricted use, distribution, and reproduction in any medium, provided the original author and source are credited.

Published By Indian Society for Education and Environment (iSee)

ISSN

Print: 0974-6846

Electronic: 0974-5645

\section{Broadband circular polarized patch antenna with harmonic suppression}

\author{
N T Markad ${ }^{1}$, Swapnali Mahadik ${ }^{2 *}$ \\ 1 Professor, Electronics engineering, Bharati vidyapeeth (Deemed to be) university, pune, \\ 411043, India \\ 2 Student, Electronics engineering, Bharati vidyapeeth (Deemed to be) university, pune, \\ 411043, India. Tel.: +91-8668385685
}

\section{Abstract}

Background/Objectives: To develop Circular Polarized (CP) patch antenna with improved bandwidth and harmonic suppression for RF energy harvesting system. Methods/Statistical analysis: A $\lambda / 4$ resonator is introduced and coupled in proximity to the radiating patch for bandwidth enhancement and high order harmonic suppression. Compared with other dual-resonance patch antennas, the proposed antenna has attractive low-profile property and simple structure. The CP can be achieved by putting arc shape slits at edge of circular patch. The structure, working principle and results we are described. Findings/ Applications: The operating bandwidth is from $1.68 \mathrm{GHz}$ to $2.95 \mathrm{GHz}(52.91 \%)$ with a reflection coefficient less than $-10 \mathrm{~dB}$ with Axial Ratio bandwidth of $550 \mathrm{MHz}(2.21 \mathrm{GHz}-2.76 \mathrm{GHz})$ while harmonic suppression over wide frequency range from 1 to $12 \mathrm{GHz}$ is achieved. The experimental and simulated results is good matching except some slight variation. Novelty/Applications: New techniques for both bandwidth enhanced and harmonic suppression and up to $4^{\text {th }}$ higher order harmonics has been suppressed. Proposed structure offers wideband CP Antenna with harmonic suppression.

Keywords: RF energy harvesting; microstrip patch antenna; harmonic suppression; circular polarization

\section{Introduction}

With the development of antenna technology, one of the focusing issues nowadays is integrating antennas and filters. Suppressing the wideband high order harmonic attracts more and more researchers' attention. Integrating filter at input front end of antenna is the common method to suppress high order harmonics ${ }^{(1)}$. Applying filters can contribute to other issues such as increasing the size, weight, and cost of the wireless device. In this way, some alternative solutions that do not increase cost or complexity for the device can be attractive. Thus, solutions that use the antenna itself to filter these higher-order modes become interesting ${ }^{(2,3)}$.

Several studies are being developed for design designing antennas able to attenuate or suppress unwanted frequencies. To suppress the second and third harmonics a spurline filter was inserted in the antenna microstrip feed line ${ }^{(4)}$. Defected ground structures (DGS) was used in patch antenna to suppress higher order harmonics ${ }^{(5-8)}$. 
Transverse slot orthogonal to the microstrip feedline is introduced as the harmonic suppression unit ${ }^{(9)}$. To improve the both bandwidth and the harmonic suppression long stub used ${ }^{(10)}$. A pair of $\lambda / 4$ stepped-impedance resonators (SIRs) in each port which is to enhance bandwidth and suppress harmonics used ${ }^{(11)}$.

In RF Energy Harvesting System due to Linear polarization of antenna, it does not get maximum ambient RF energy. Thus using Circular Polarized (CP) antenna, we can avoid wrong polarization which results collect maximum RF energy ${ }^{(12-14)}$. A circularly polarized (CP) microstrip antenna with embedded slots is designed which efficiently attains harmonics suppression ${ }^{(15)}$. CP Antennas offers lots of applications in modern-day wireless communication ${ }^{(16,17)}$.

The antenna structures in ${ }^{(2-14)}$, with higher order mode suppression. However, these antennas have very low bandwidth; some antenna cannot be circular polarized.

In this work, we design a new antenna with harmonic rejection operate at $2.45 \mathrm{GHz}$. The harmonic rejection has been accomplished by using $\lambda / 4$ resonator with partial gnd and a capacitive feed line. This structure can achieve harmonic suppression function so that harmonics up to $4^{\text {th }}$ order can be suppressed. The measured results show good agreement with the simulated results

\section{Material and Methods}

\subsection{Geometry and design}

The structure of the proposed CP patch antenna is shown in Figure 1. This antenna is designed on a substrate with a relative permittivity of 4.4 and thickness of $h=1.5 \mathrm{~mm}$. The size of the resonator is ( $\mathrm{Lr})$ that of the $1 / 4$ resonator is chosen. The radius of circular patch (a) is calculated by below equations ${ }^{(18)}$.

$$
\operatorname{Lambda}(\lambda)=\mathrm{c} / \mathrm{f}=3 \times 10^{\wedge} 8 / 2.4 \times 10^{\wedge} 9
$$

$$
(\lambda)=125 \mathrm{~mm} \text { at } 2.4 \mathrm{GHz}
$$

The radius of circular patch is given by,

$$
a=F\left\{1+\frac{2 h}{\pi F \varepsilon_{r}}\left[\ln \left(\frac{\pi F}{2 h}\right)+1.7726\right]\right\}^{-1 / 2}
$$

Where,

$$
\begin{aligned}
F & =\frac{8.791 \times 10^{9}}{f_{r} \sqrt{\varepsilon_{r}}} ; f_{r} \text { in GHz, h in mm } \\
Z_{0} & =\frac{60}{\sqrt{\varepsilon_{\mathrm{r}}}} \ln \left(8\left(\frac{H}{W_{\mathrm{f}}}\right)+0.25\left(\frac{W_{\mathrm{f}}}{H}\right)\right)
\end{aligned}
$$

We get $\mathrm{Wf}=2.8 \mathrm{~mm}$

Feed and resonant length is given by

Feed length $(\mathrm{L} 50)=\lambda / 4^{*}$ sqrt $(4.4)$

Resonant length $(\mathrm{Lr})=\lambda / 4$

$\mathrm{Ls}=\mathrm{L}+2^{\star} 6 \mathrm{~h}=28.4+2^{*} 6^{\star} 1.6=49 \mathrm{~mm}$

$\mathrm{Ws}=\mathrm{W}+2^{\star} 6 \mathrm{~h}=38+2^{*} 6^{*} 1.6=59 \mathrm{~mm}$

For the purpose of bandwidth enhancement, the resonance of the $1 / 4$ resonator with partial gnd, which is close to the TM10 resonance of the patch antenna, is introduced. This can efficiently improve the operating bandwidth. In addition, to achieve a better impedance matching, the partial gnd plane is used as shown in [ Figure 1]. The length of the resonator can be tuned to suppress the certain high-order resonance of the patch antenna. Finally, by optimization, the size parameters of this proposed $\mathrm{CP}$ patch antenna are as shown in Table 1. [ Figure 2 ] shows traditional CP antenna and [ Figure 3 ] shows proposed CP antenna 


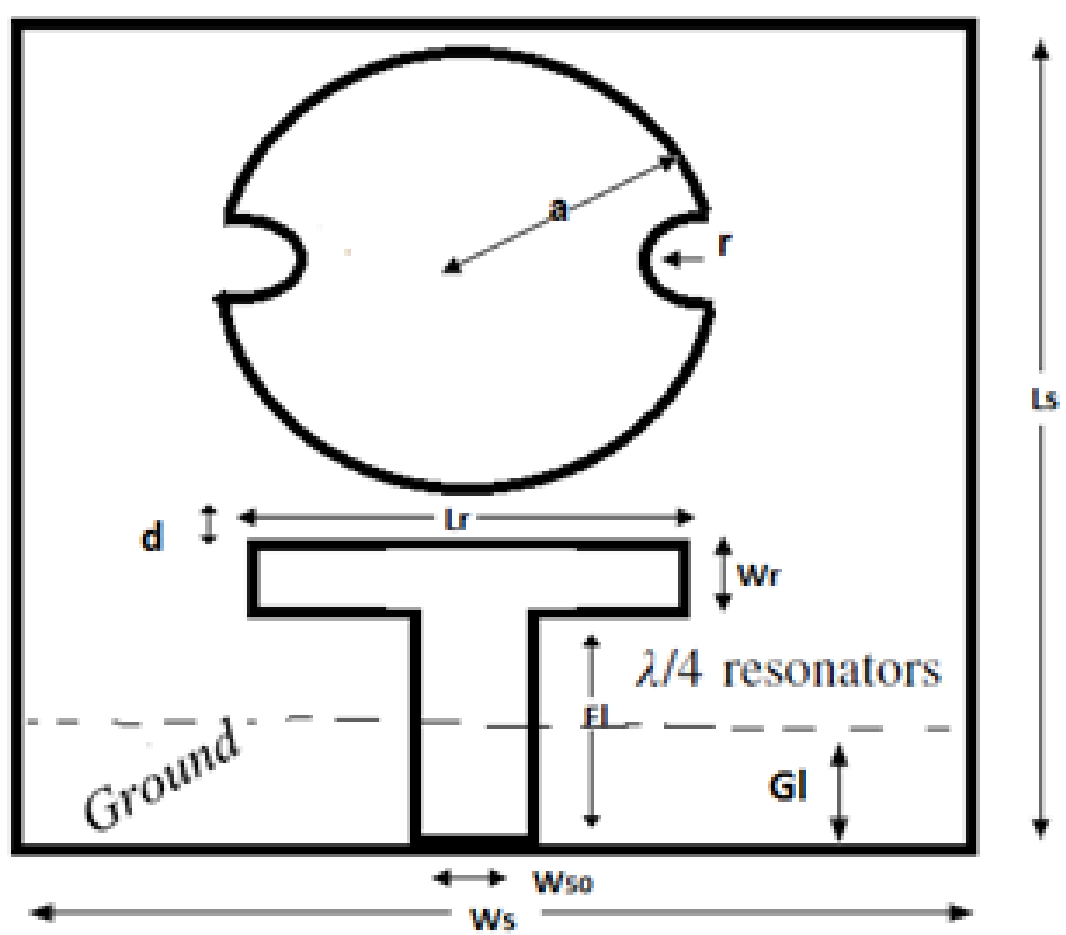

Fig 1. Geometry of the proposed wideband $\mathrm{CP}$ antenna

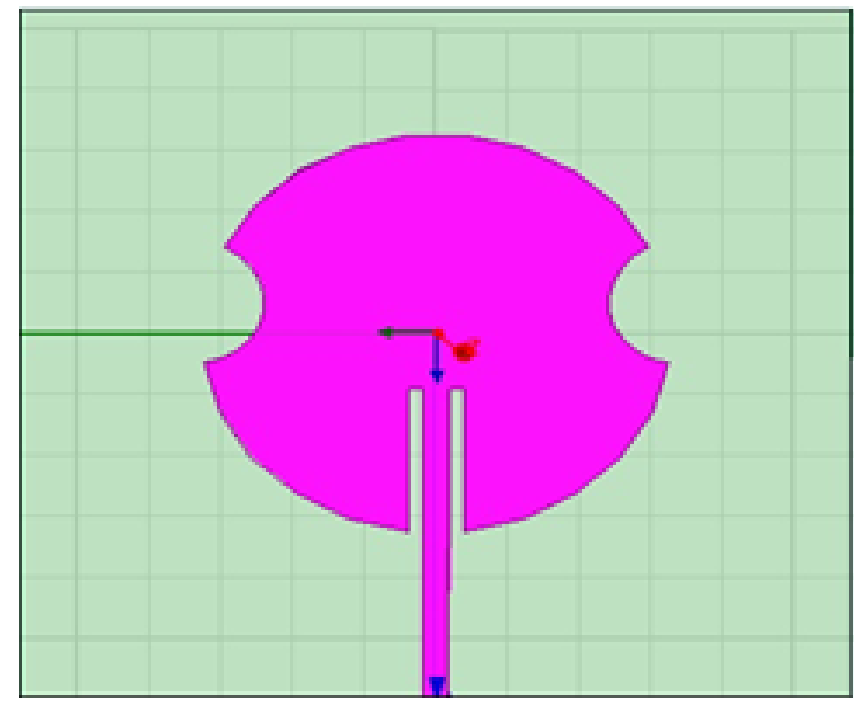

Fig 2. Traditional circular polarized patch Antenna

Table 1. Optimized dimension of proposed CP antenna

\begin{tabular}{|c|c|c|c|c|c|}
\hline Parameters & Ls & Ws & a & $\mathrm{Lr}$ & $\mathrm{Wr}$ \\
\hline Dimensions (mm) & 56.0 & 56.0 & 14.5 & 29.0 & 1.0 \\
\hline Parameters & $\mathrm{Fl}$ & W50 & $\mathrm{d}$ & $\mathrm{Gl}$ & $\mathrm{r}$ \\
\hline Dimensions (mm) & 18.5 & 2.8 & 1.5 & 12.0 & 5.0 \\
\hline
\end{tabular}




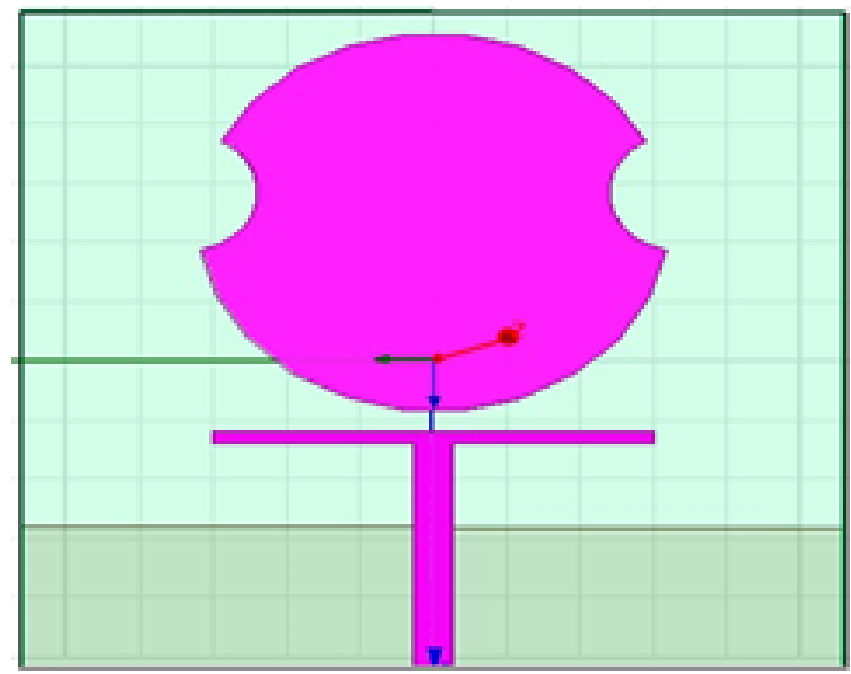

Fig 3. Proposed circular polarized antenna

\section{Results and Discussion}

\subsection{Effect of simulated return loss of the proposed CP antenna and traditional CP antenna}

The Simulation results of proposed CP antenna has been carried out in HFSS. [ Figure 4 ] presents the simulated reflection coefficient of the proposed CP antenna, the traditional CP antenna after introducing the capacitive coupling feed, high-order resonant modes at $5.0 \mathrm{GHz}, 7.1 \mathrm{GHz}, 9.5 \mathrm{GHz}$, and $11.0 \mathrm{GHz}$ are significantly suppressed.

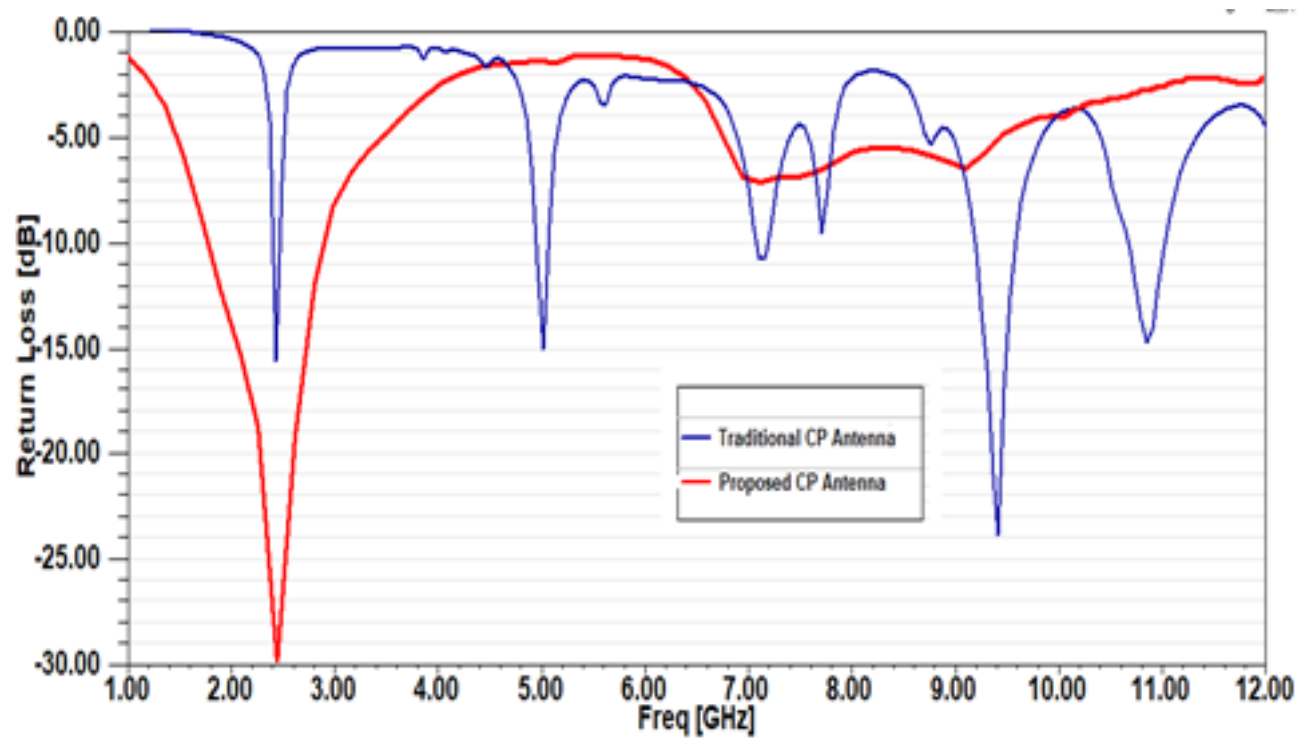

Fig 4. Simulated return loss of the proposed CP antenna and traditional CP antenna

\subsection{Effect of coupling gap (d) on return loss}

Meanwhile, effect of coupling gap (d) can be observed in [ Figure 5 ], which indicates that the gap is important parameter of the proposed CP patch antenna for wider bandwidth. Comparing the results of coupling gap $\mathrm{d}=1.0 \mathrm{~mm}, 1.5 \mathrm{~mm}$ and $2.0 \mathrm{~mm}$. The optimum gap $\mathrm{d}=1.5 \mathrm{~mm}$ (blue graph), we got maximum bandwidth in proposed CP antenna. 


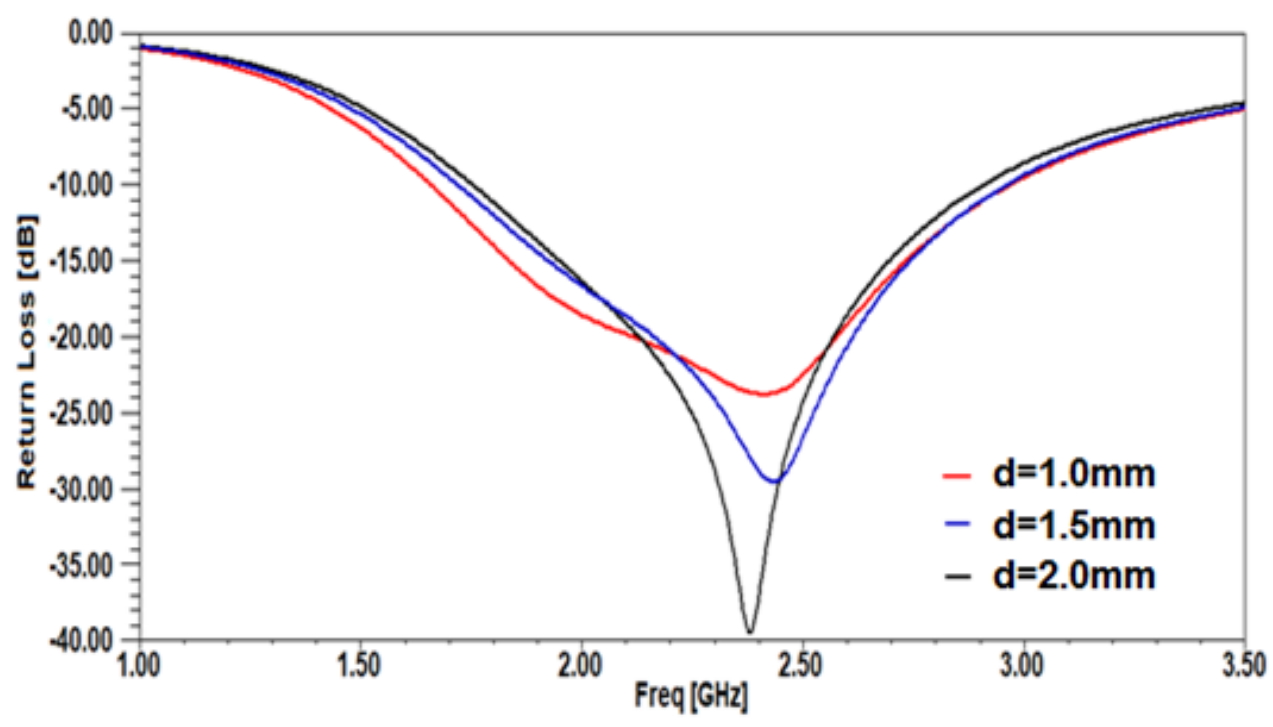

Fig 5. Effect of coupling gap (d) on return loss

\subsection{Effect of resonator length (Lr) on return loss}

The effect of resonator length (Lr) can be observed in [ Figure 6 ], which indicates that the resonator length is important parameter of the proposed $\mathrm{CP}$ patch antenna for controlling resonating frequency. If the resonator length is increasing, then freq shift to at lower side around $2.3 \mathrm{GHz}$ (blue graph) and decreasing resonant length the freq shift to higher side at $2.6 \mathrm{GHz}$ (green graph). The optimized resonator length $\mathrm{Lr}=29 \mathrm{~mm}$ (red graph), we got desired freq $2.45 \mathrm{GHz}$.

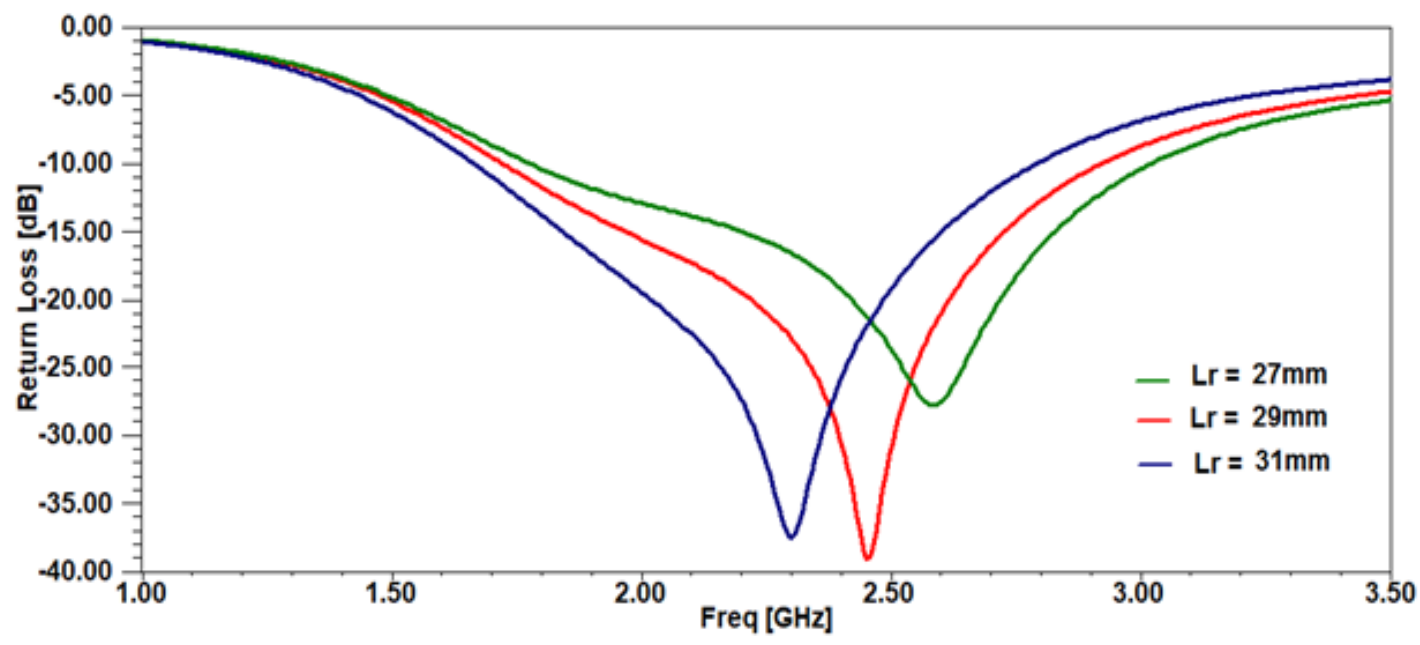

Fig 6. Effect of resonator length (Lr) on Return Loss

\subsection{Effect of radius of circular patch (a) on return loss}

The effect of radius of circular patch (a) can be observed in [ Figure 7 ], which indicates that the radius of circular patch is important parameter of the proposed CP patch antenna for better impedance matching. If the radius of antenna is increasing, then the return loss is $-22.5 \mathrm{~dB}$ at $2.40 \mathrm{GHz}$ (blue graph) and decreasing radius of antenna the return loss is $-36.5 \mathrm{~dB}$ at $2.5 \mathrm{GHz}$ (green graph). The optimized radius of antenna $\mathrm{a}=14.5 \mathrm{~mm}$ (red graph), we got freq minimum return loss $-39.3 \mathrm{~dB}$ at $2.45 \mathrm{GHz}$. 


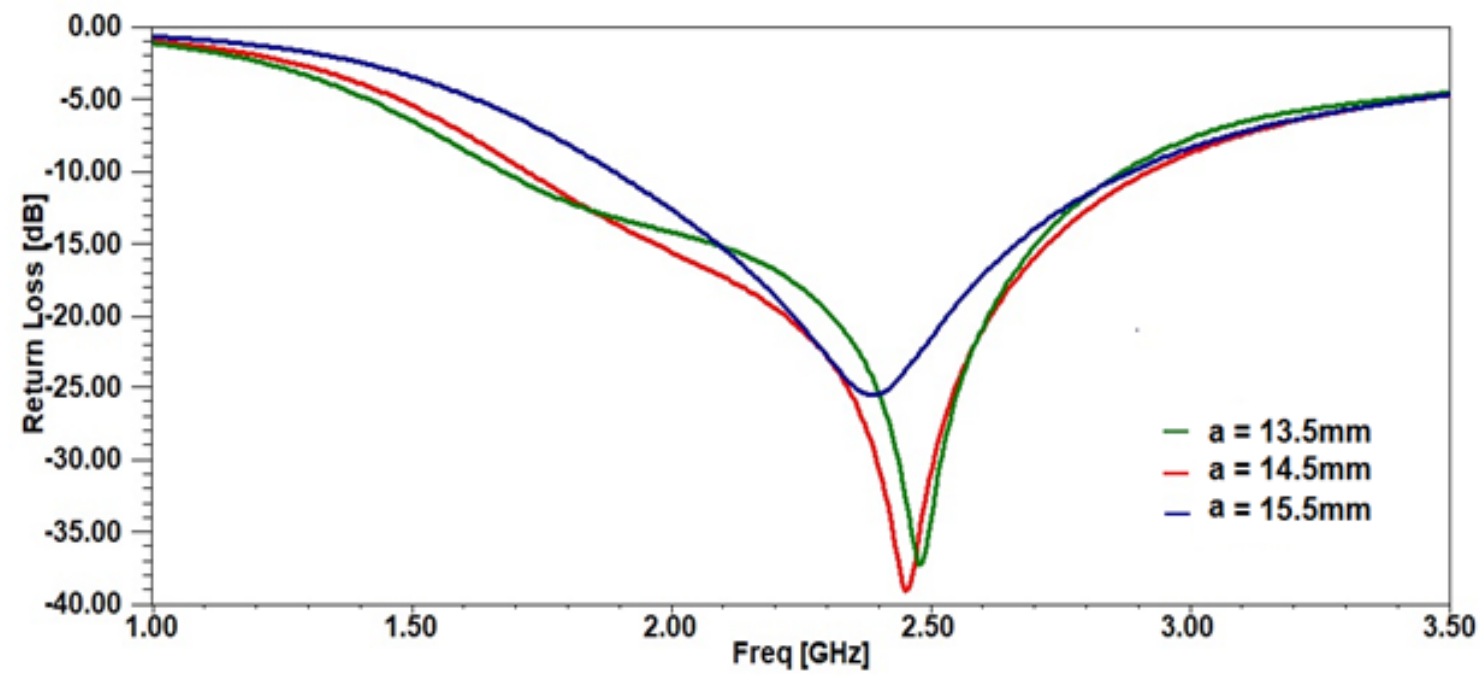

Fig 7. Effect of radius of circular patch (a) on return loss

\subsection{VSWR of Proposed CP Antenna}

[ Figure 8 ] VSWR of Proposed CP Antenna. The Simulated bandwidth of the proposed CP antenna in terms of VSWR is $1.68-2.95 \mathrm{GHz}(52.91 \%)$.

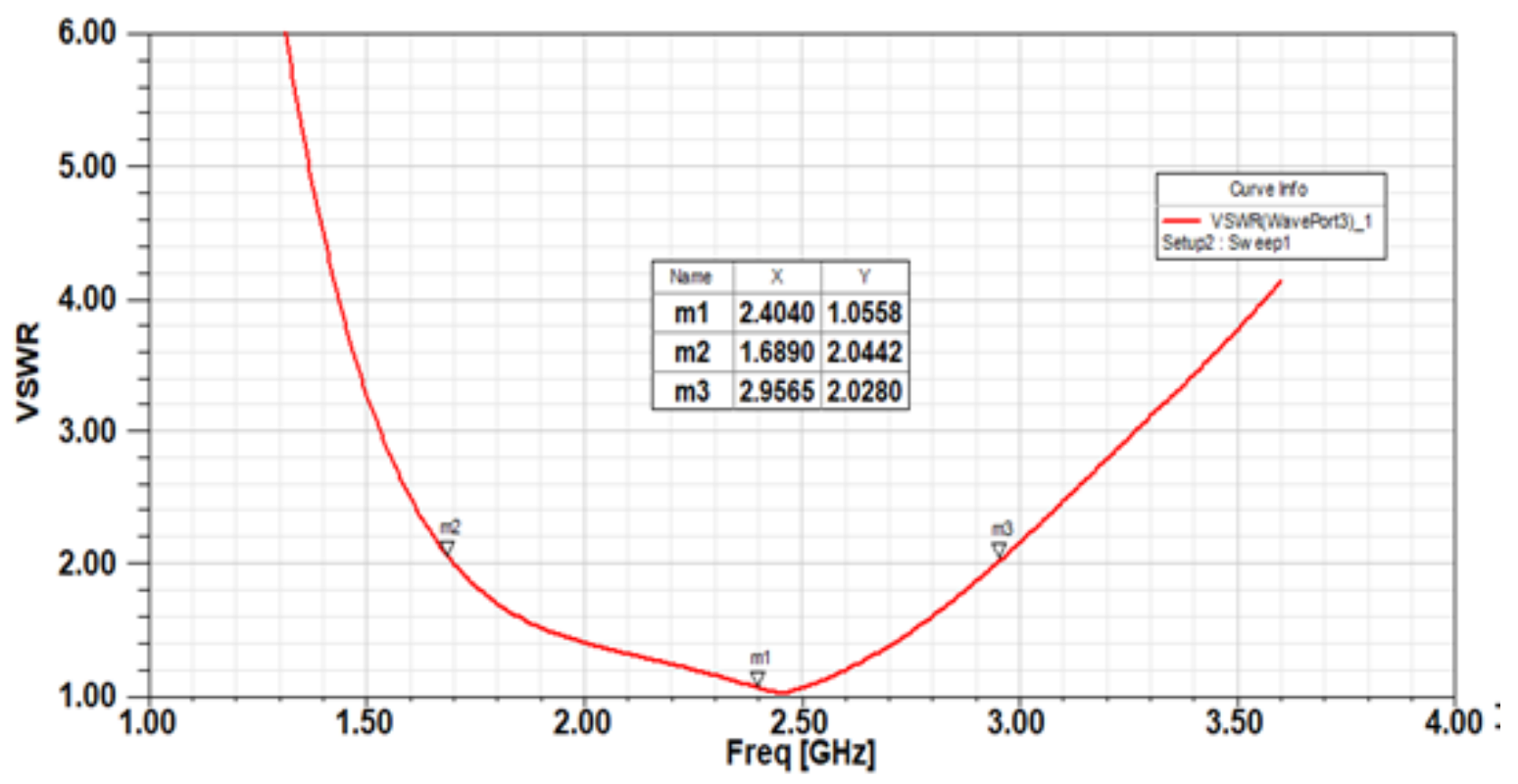

Fig 8. VSWR of proposed CP antenna

\subsection{Radiation pattern $\mathrm{E}$ and $\mathrm{H}$ plane of proposed CP antenna}

[ Figure 9 ] it is observed that the radiation patterns of proposed $\mathrm{CP}$ antenna are bidirectional in E-plane \& omnidirectional in $\mathrm{H}$ plane at freq $2.45 \mathrm{GHz}$. It can be observed that the gain of the proposed $\mathrm{CP}$ antenna is $2.5 \mathrm{dBi}$ at $2.45 \mathrm{GHz}$. 


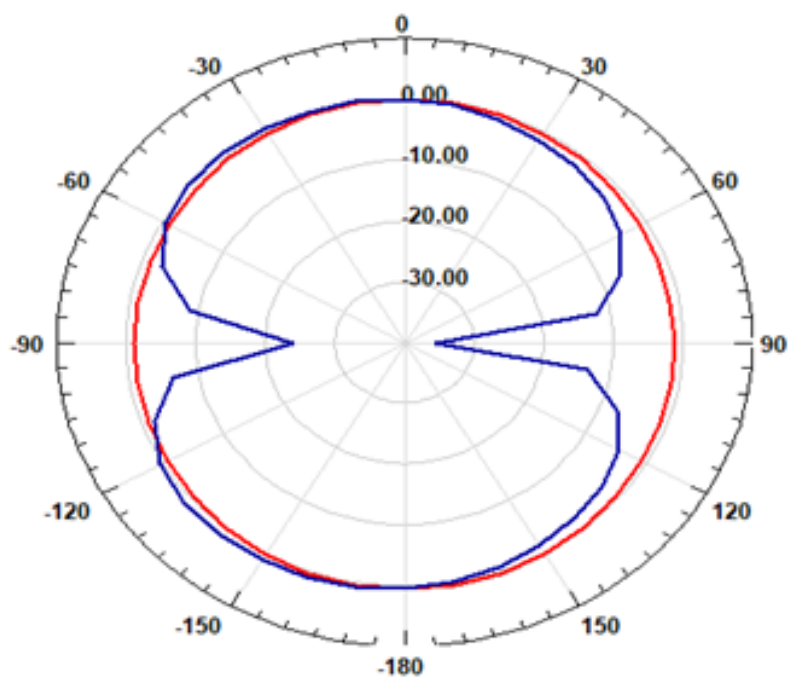

Fig 9. Radiation pattern $\mathrm{E}$ and $\mathrm{H}$ plane of proposed $\mathrm{CP}$ antenna

\subsection{Co and cross polarization in E and $\mathrm{H}$ plane of proposed CP antenna}

[ Figure 10 ] The simulated co- and cross-polarized radiation patterns of proposed CP antenna in E-plane \& H-plane at the resonant frequency $2.45 \mathrm{GHz}$ are plotted in [ Figure 10]. It shows that the $\mathrm{CP}$ antenna has a bidirectional radiation pattern in E-plane and omnidirectional in H-plane [ Figure 10a], illustrates simulated co- and cross-polarized radiation patterns of proposed antenna in E-plane, at the resonant frequency $2.45 \mathrm{GHz}$. The cross-polarization level is more than $40 \mathrm{~dB}$ below than the co-polarization level. [ Figure 10b], illustrates simulated co- and cross-polarized radiation patterns of proposed antenna in $\mathrm{H}$-plane, at the resonant frequency $2.45 \mathrm{GHz}$. The cross-polarization level is more than $42 \mathrm{~dB}$ below than the co-polarization level.

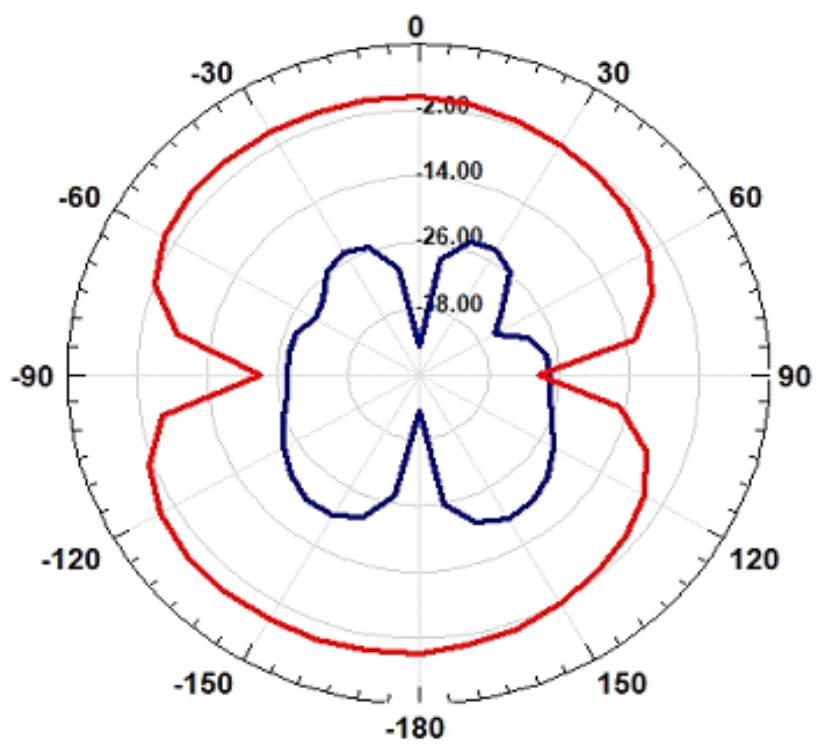

Co-Polarization - Cross-Polarization

(a) E-plane 


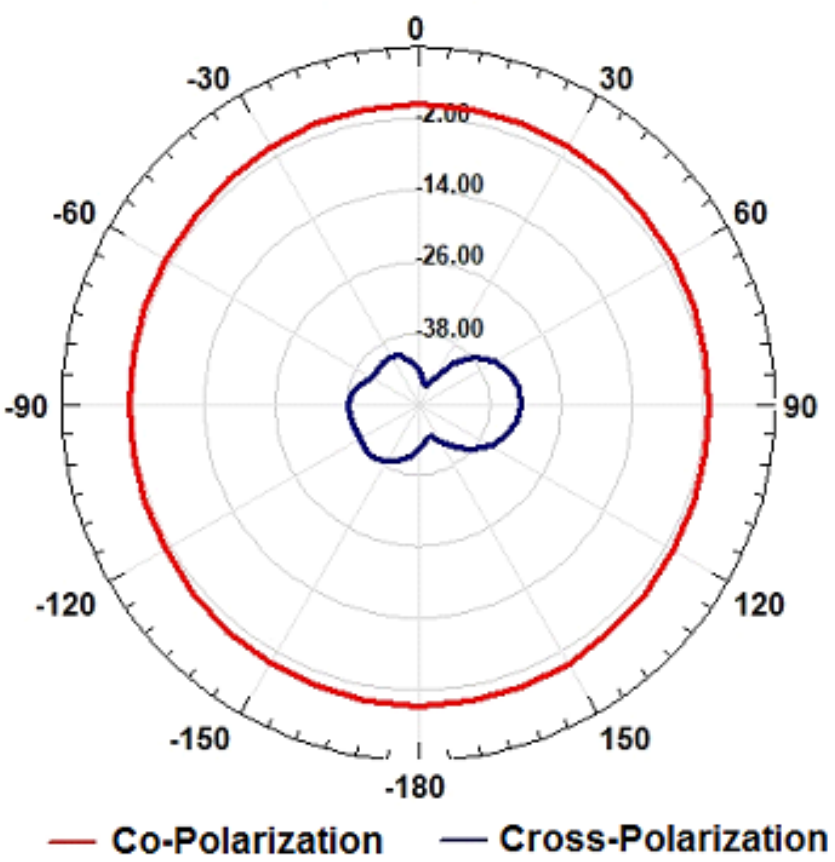

(b) H-plane

Fig 10. Co-Cross polarization of proposed $\mathrm{CP}$ antenna at $2.45 \mathrm{GHz}(\mathrm{a})$ E-plane and (b) H-plane.

\subsection{Axial ratio of proposed CP antenna}

[ Figure 11] The proposed CP antenna has axial ratio (AR) bandwidth of $550 \mathrm{MHz}$ i.e. $22.91 \%$ covering the frequency range of $(2.21 \mathrm{GHz}-2.76 \mathrm{GHz})$. The antenna has a good performance in term of AR.

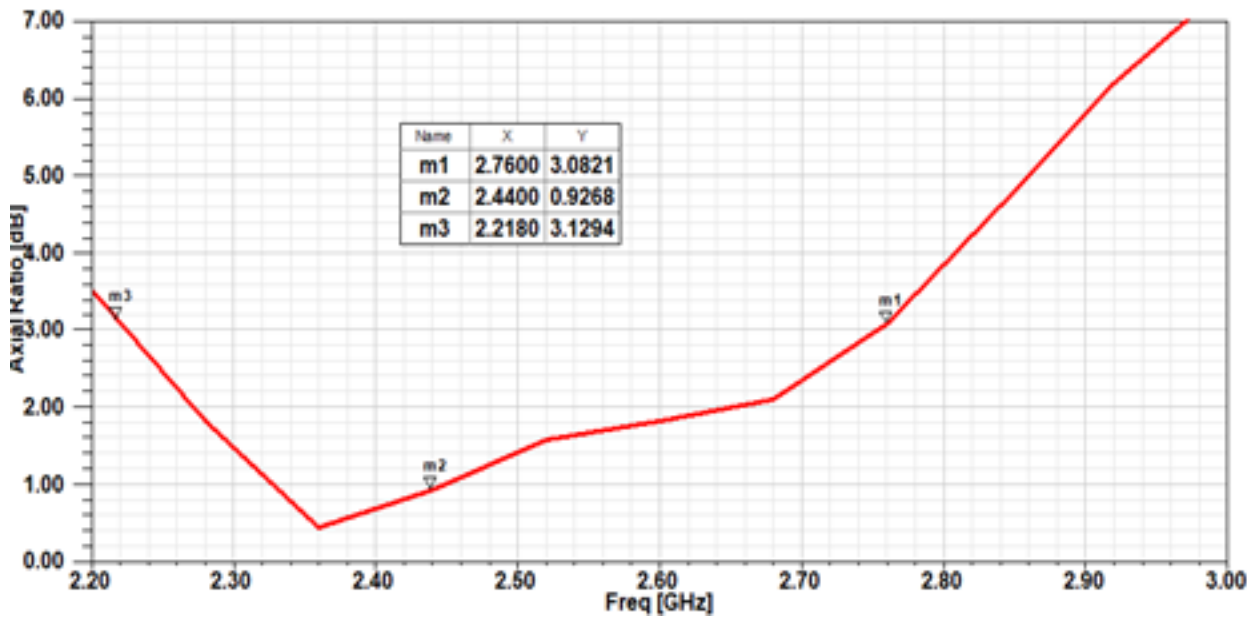

Fig 11. Axial ratio of proposed $\mathrm{CP}$ antenna

\subsection{Surface current distributions}

The current distribution of the Proposed Vs. traditional CP antenna at $5.0 \mathrm{GHz}$ and $9.5 \mathrm{GHz}$ is presented in [ Figure 12 ]. Red colour indicates maximum current along the edge of radiating patch. This means that in proposed $\mathrm{CP}$ antenna there is no second 
and third harmonics present.

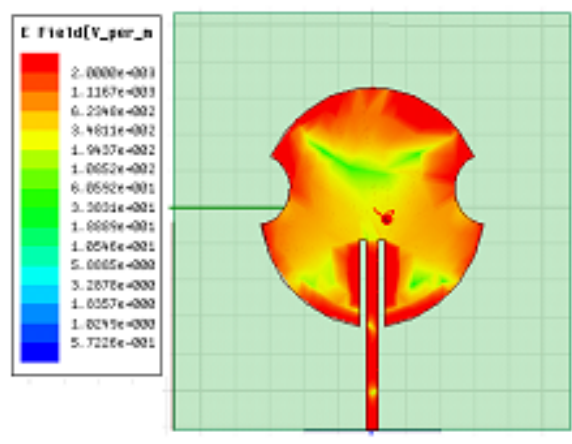

(i)Traditional CP

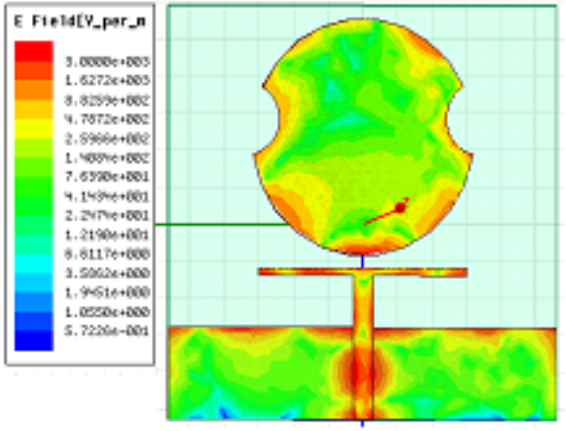

(ii) Proposed CP

(a) Freq $=5.0 \mathrm{GHz}$

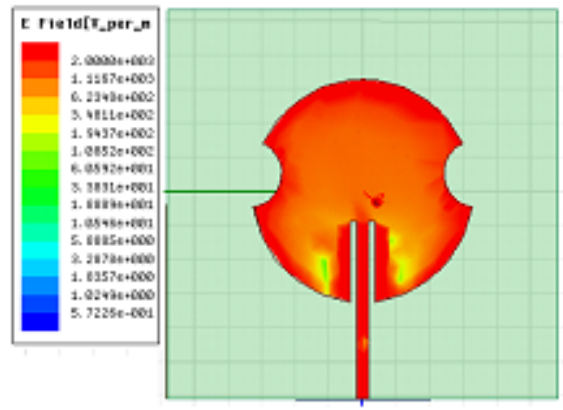

(iii)Traditional CP

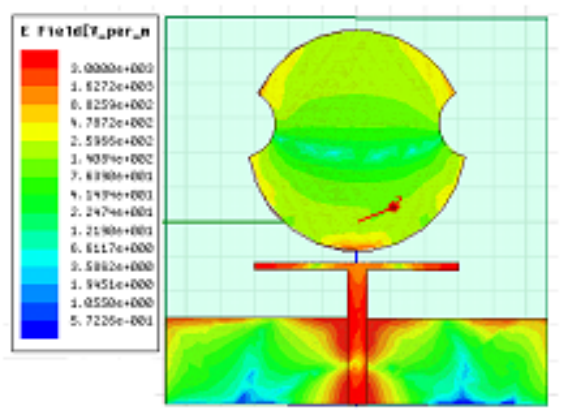

(iv) Proposed CP

\section{(b) Freq $=9.5 \mathrm{GHz}$}

Fig 12. Surface 3 current distributions (a) $5.0 \mathrm{GHz}$ (b) $9.5 \mathrm{GHz}$

\subsection{Comparison Table}

As seen the [ Table 2 ], To improve the performance of this antenna, a pair of $\lambda / 4$ microstrip line resonators is introduced. Traditional CP patch antenna, and proposed CP patch antenna are described. It concludes that proposed CP patch antenna technique's both bandwidth \& harmonics suppression of antenna are improved.

Table 2. Comparison table of traditional Vs proposed CP antenna

\begin{tabular}{lllllll}
\hline Sr. No. & Results & Freq $(\mathrm{GHz})$ & Return Loss $(\mathrm{dB})$ & VSWR & BW $(\mathrm{MHz})$ & Gain $(\mathrm{dB})$ \\
\hline 1. & Traditional CP Patch Antenna & 2.45 & -15.60 & 1.39 & 70 & 4.6 \\
2. & Proposed CP Antenna & 2.44 & -29.87 & 1.06 & 1260 & 2.5 \\
\hline
\end{tabular}

\subsection{Measurement results}

The Proposed CP Patch antenna has been fabricated and tested using VNA. The Measurement results of proposed circular patch antenna getting bandwidth of $1220 \mathrm{MHz}$ at freq $2.47 \mathrm{GHz}$. It shows there is harmonic reduction through entire freq band form 1-10GHz. The simulated Vs measured return loss proposed circular patch antenna has been shown in [ Figure 13 ]. 
The Measured return loss characteristics of the proposed patch antenna in [ Figure 10], indicated that the return loss is below $-10 \mathrm{~dB}$ in the operating freq band from $1.94 \mathrm{GHz}-3.16 \mathrm{GHz}$ and fractional percentage $\mathrm{BW}$ is around $50.83 \%$.

[ Figure 14] shows fabricated Prototype Proposed CP Patch antenna.

Comparison of the proposed CP antenna with reported state of art designs are listed in [ Table 3 ]. The proposed CP antenna offers large bandwidth as compared to all other antennas reported table in ${ }^{(1-5)(9)(11)(12)} \&^{(16)}$. The proposed antenna offers Circular Polarization $(\mathrm{CP})$ compared to antenna reported table in ${ }^{(1-5)}$. Also, upto $4^{\text {th }}$ higher order harmonic suppression achieved in proposed antenna.

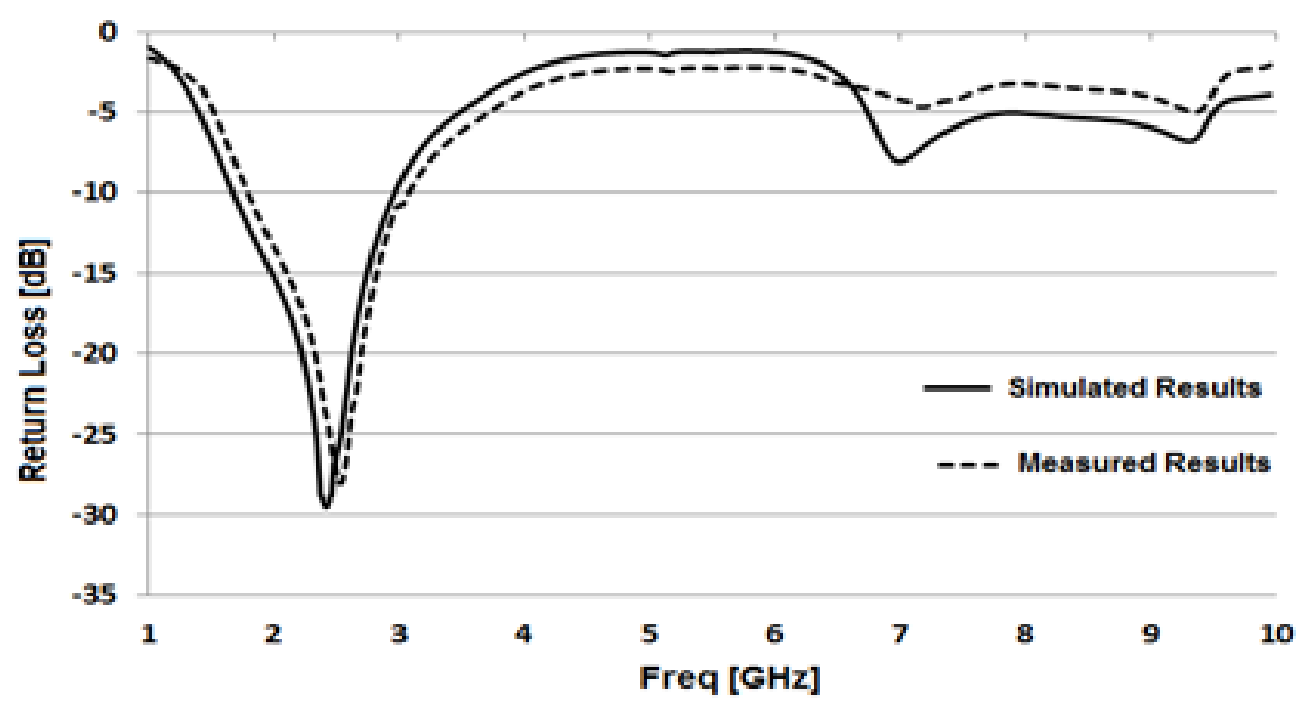

Fig 13. Simulated Vs Measured Return loss of proposed CP antenna

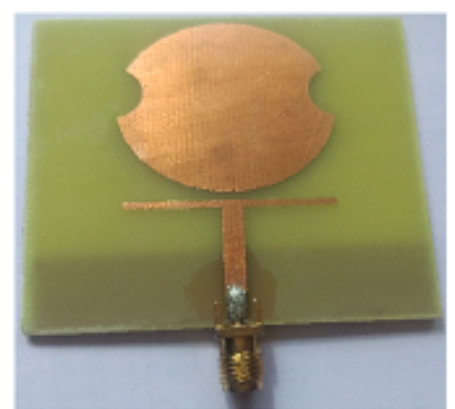

(a)TOP View

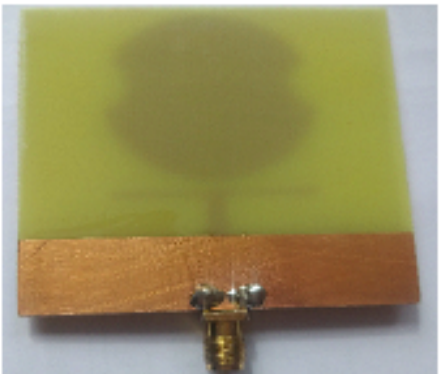

(b) BOTTOM View

Fig 14. Fabricated prototype proposed $\mathrm{CP}$ patch antenna

Table 3. Comparison of proposed CP antenna with other state of art designs

\begin{tabular}{llllll}
\hline $\begin{array}{l}\text { Year and Ref- } \\
\text { erence }\end{array}$ & $\begin{array}{l}\text { No. of higher order } \\
\text { modes Suppressed }\end{array}$ & $\begin{array}{l}\text { Fundamental Fre- } \\
\text { quency }(\mathrm{GHz})\end{array}$ & BW $(\mathrm{MHz})$ & Polarization & Techniques used \\
\hline $2020^{(1)}$ & 2 & 2.4 & 100 & Linear & Defected Ground Structure(DGS) \\
$2019^{(2)}$ & 3 & 2.4 & 80 & Linear & DGS \\
$2019^{(3)}$ & 2 & 3.5 & 90 & Linear & Defected Microstrip Structure (DMS) \\
\hline
\end{tabular}

Continued on next page 


\begin{tabular}{|c|c|c|c|c|c|}
\hline \multicolumn{6}{|c|}{ Table 3 continued } \\
\hline $2017^{(4)}$ & 3 & 2.4 & 80 & Linear & Spur-Line Filter \\
\hline $2018^{(5)}$ & 2 & 2.4 & 80 & Linear & DGS \\
\hline $2018^{(9)}$ & 3 & 2.4 & 500 & Linear & Slotted \\
\hline $2018^{(11)}$ & 2 & 3.5 & 200 & Circular & $\begin{array}{l}\lambda / 4 \text { Stepped-Impedance resonators } \\
\text { (SIRs) }\end{array}$ \\
\hline $2018^{(12)}$ & 2 & 2.4 & 300 & Circular & Slot and stubs multilayer \\
\hline $2018^{(16)}$ & 3 & 2.4 & 90 & Circular & Slot with differential feed \\
\hline $\begin{array}{l}\text { Proposed } \\
\text { work }\end{array}$ & 4 & 2.4 & 1260 & Circular & $\begin{array}{l}\lambda / 4 \text { resonator with capacitive feed and } \\
\text { partial gnd }\end{array}$ \\
\hline
\end{tabular}

\section{Conclusion}

A Circular Polarized microstrip-fed patch antenna with improved bandwidth and harmonic suppression has been proposed. Compared with the conventional microstrip-fed antenna, a 1/4 resonator and partial gnd are introduced, respectively, to enhance the impedance bandwidth and harmonic suppression. The bandwidth of proposed CP antenna around $1260 \mathrm{MHz}$ $(1.69-2.95 \mathrm{GHz})$ is 18 times higher than traditional CP antenna. The proposed CP antenna has axial ratio (AR) bandwidth of $550 \mathrm{MHz}$ i.e. $22.91 \%$ covering the frequency range of $(2.21 \mathrm{GHz}-2.76 \mathrm{GHz})$. The experimental and simulated results offer good matching except some slight variation.

\section{References}

1) Shah SM, Mohamad M, Hamzah SA, Abidin ZZ, Seman FC, Katiran N, et al. A 2.45 GHz microstrip antenna with harmonics suppression capability by using defected ground structure. Bulletin of Electrical Engineering and Informatics. 2020;9(1):387-395. Available from: https://dx.doi.org/10.11591/eei.v9i1.1847.

2) Ma W. A Microstrip Patch Antenna Design with Harmonic Rejection Using Defected Ground Structure. In: 2019 IEEE MTT-S International Wireless Symposium (IWS). 2019;p. 1-3. Available from: https://doi.org/10.1109/IEEE.2019.19296455.

3) Yi L, Yu H, Yu Y. Harmonic Suppression of Microstrip Antenna by Defected Microstrip Structure. In: 2019 International Symposium on Antennas and Propagation (ISAP). 2019;p. 1-3. Available from: https://doi.org/10.1109/IEEE-IWS.2019.210888447.

4) Batista LFF, Souza LD. Harmonic Suppression in Microstrip Patch Antenna Using Spur-Line Filter . IEEE Antennas Wireless Propag Lett. 2017.

5) Pattapu U, et al. A $2.45 \mathrm{GHz}$ harmonic suppression array antenna for rectenna application. In: and others, editor. 3rd International Conference on Microwave and Photonics (ICMAP). 2018. Available from: https://doi.org/10.1109/ICMAP.2018.8354541.

6) Elftouh H, Naima T, Aicha M, Zakriti A, Bakkali M. Suppression of Harmonic of Microstrip Patch Antenna Using Defected Ground and Defected Microstrip Structure. Procedia Manufacturing. 2019;32:653-660. Available from: https://doi.org/10.1016/j.promfg.2019.02.267.

7) Souza FAAD, De ALP, Campos S, Neto AG. Higher Order Mode Attenuation in Microstrip Patch Antenna with DGS H Filter Specification from 5 to $10 \mathrm{GHz}$ Range. Journal of Microwaves, Optoelectronics and Electromagnetic Applications. 2020;19(2). Available from: http://dx.doi.org/10.1590/217910742020v19i2823.

8) Sena FDCB, Silva JPD. Harmonic suppression using optimised hexagonal defected ground structure by genetic algorithm. IET Microwaves, Antennas \& Propagation. 2019;12(10):1645-1648. Available from: https://doi.org/10.1049/iet-map.2017.0733.

9) Li W, Wang Y, You B, Shi Z, Liu QH. Compact Ring Slot Antenna with Harmonic Suppression. IEEE Antennas and Wireless Propagation Letters. 2018;17:2459-2463. Available from: https://doi.org/10.1109/LAWP.2018.2877974.

10) Zang Y, Zhai H, Xi L, Li L. A Compact Microstrip Antenna With Enhanced Bandwidth and Ultra-Wideband Harmonic Suppression. IEEE Transactions on Antennas and Propagation. 2019;67(3):1969-1974. Available from: https://dx.doi.org/10.1109/tap.2019.2891757.

11) Liu B, Li H, Cheng C. A Coaxial Fed Dual-Polarized Patch Antenna with Wide-Bandwidth and Good Harmonic Suppression. In: International Conference on Microwave and Millimeter Wave Technology (ICMMT). 2018;p. 1-3. Available from: https://doi.org/10.1109/ICMMT.2018.8563790.

12) Sabran MI, Rahim SKA, Leow CY, Soh PJ, Chew BW, Vandenbosch GAE. Compact circularly polarized truncated square ring slot antenna with suppressed higher resonances. PLOS ONE. 2017;12(2). Available from: https://dx.doi.org/10.1371/journal.pone.0172162.

13) Chandrasekaran KT, Agarwal K, Nasimuddin A, Mittra A, Karim R. Compact Dual-Band Metamaterial-Based High-Efficiency Rectenna: An Application for Ambient Electromagnetic Energy Harvesting. IEEE Antennas and Propagation Magazine. Available from: https://doi.org/10.1109/map.2020.2982091.

14) Divakaran SK, Krishna DD, Nasimuddin. RF energy harvesting systems: An overview and design issues. International Journal of RF and Microwave Computer-Aided Engineering. 2019;29(1). Available from: https://dx.doi.org/10.1002/mmce.21633.

15) Banerjee U, Karmakar A, Saha A. A review on circularly polarized antennas, trends and advances. International Journal of Microwave and Wireless Technologies. 2020;12(9):922-943. Available from: https://dx.doi.org/10.1017/s1759078720000331.

16) Kumar D, Chaudhary K. Design of Differential Source Fed Circularly Polarized Rectenna with Embedded Slots for Harmonics Suppression. Progress In Electromagnetics Research C. 2018;84:175-187. Available from: https://doi.org/10.2528/PIERC18021401.

17) Kirov G. Evaluation of the frequency bandwidth and gain properties of antennas: Characteristics of circularly polarized microstrip antennas. IEEE Antennas and Propagation Magazine. Available from: https://doi.org/10.1109/MAP.2020.2976912.

18) Hasan Z, Ashiq Z, Ahmed A. Design and Fabrication of a Circular Microstrip Patch Antenna for GPS Application. 8. 54-57. IJECT. 2017;8(3). 